\title{
She looks away, he looks back : translation as reflection of our times.
}

\section{Camille Akmut}

Collected thoughts on what it means to translate, in preparation for an upcoming translation. We argue : "In certain songs, we hear our own lyrics.",

"Translations are reflections of our times, and ourselves - and yourselves." and, based on Martha, "She looks away, he looks back." 


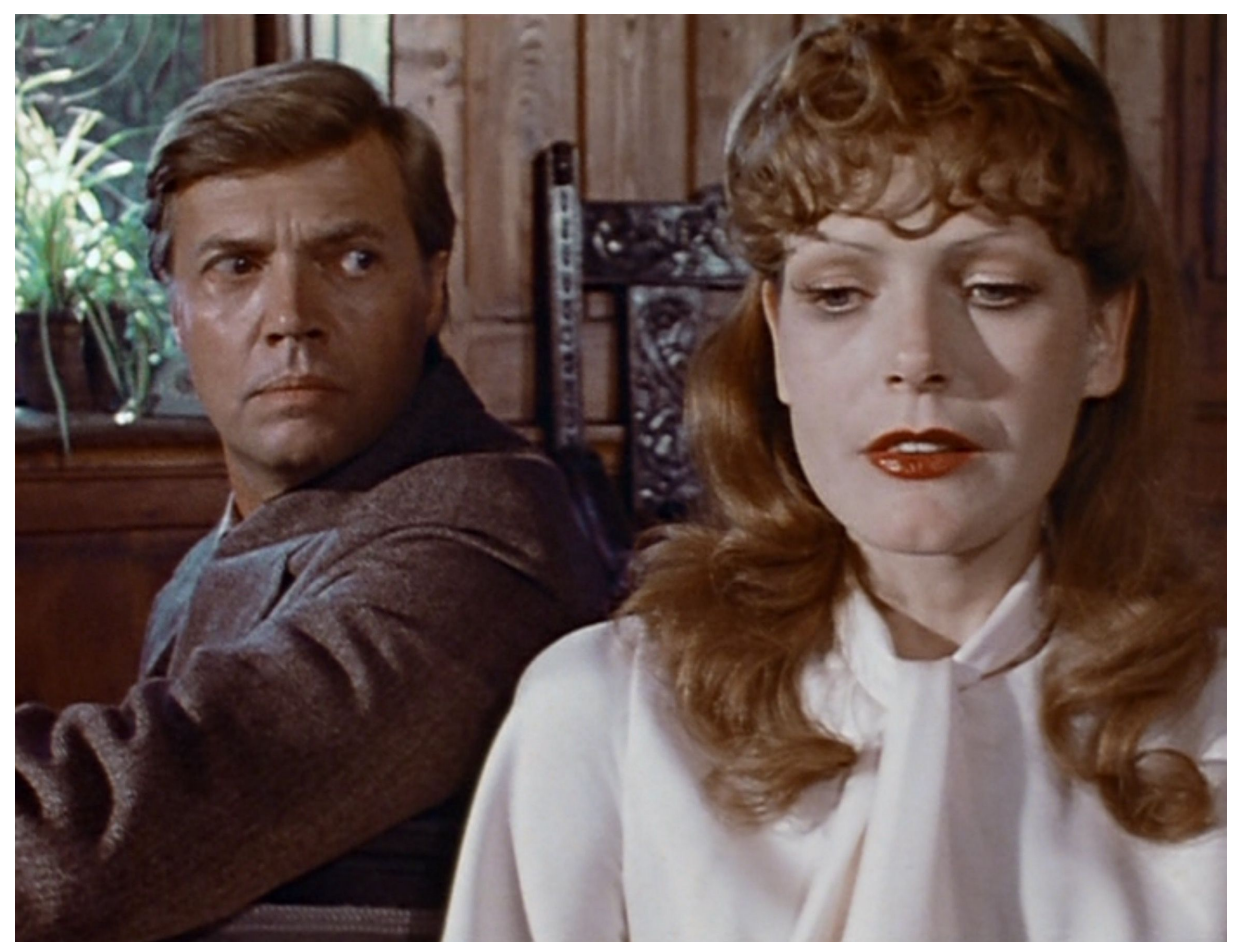

Figure 1: Martha (1974) : She looks away, he looks back. 


\section{The reader played}

In certain songs, we hear our own lyrics.

Like in Unknown Pleasures.

Translation is very much like so.

There is a premise of abuse that is inherent to all translations. "We hurt the ones we love most" - recognized a modern heroine.

The premise alone let's you know so much :

"In certain songs, we hear our own lyrics" we said. We repeat ourselves too. A few examples now :

In The Lonesome Death of Hattie Carroll, a song so great we have to put in italics reserved to works of literature, we cannot help ourselves, we only hear :

\section{"Hattie Carroll was a maid in the kitchen."}

But, apparently, Dylan had meant "of the kitchen". But, "of" sounds a bit too noble for our taste... We associate "of" with Zanzinger instead.

Would you be mad at us if we had translated it so from a foreign language, knowing it was "of(f)"?

Or, would you feel, on the contrary, that you had gained something - more - from "in"?

Maybe you would feel that, in some strange way, we had been more right than even the author knew themselves to be right. Even, if they said so?

The fact that some things escape us : is the very basis for the history of art - as we know. Otherwise, a mere encyclopedia of birth and death dates would be enough to us, even those we lack - and what kind of a world would like a history like that. - only an empty one.

Even if Kubrick, who knew much better than to do this, told anyone such and such film of his, had meant such and such things... It would be neither.

Translation is not for the faint of heart.

Everyone is a master of their own lives?

Unknown pleasures: "abuse", "heroine", "hurt", "mad", "strange", "death", "empty", "faint", "unknown" ...

And, meanwhile, this had all been going on right in front of your eyes, the whole time. We even warned you. (Multiple times!)

And, you will now perhaps agree with us, when we repeat that: "The fact that some things escape us is the basis of art history." Meanwhile, we changed this sentence a little bit. Removed some things, added others.

But, no more tricks we promise! Trust us : But, more importantly, trust yourself.

"Hattie Carroll was made, killed in the kitchen." 
We will perhaps one day find the audacity, and courage, and truth, of writing so. - loveless, and reckless.

\section{Mirror of yourselves}

In another song, we hear as if it were truth :

"I've been waiting for a guy to take me by the hand; and, make me feel the pleasures of another man."

This, we can guarantee, we are not alone in hearing. Whatever, it is much better, so. - and, not "perhaps" only. - or, in addition to being so, perhaps.

But, perhaps Ian Curtis had meant it exactly like that. We'll never know, unless someone translated it.

In another yet, we hear Baldwin's inverted echoes...

In translation acts, the truth is no better than the truth.

We like the mistakes of Panofsky over, in addition to the truth.

We like the Divine Comedy most in the translation of Mark Musa. It is a book of both, and none, like great translations.

We turn writings, like Intellectuals in the Middle Ages, or "The School of Vienna at (the Congress of) Prague", or Inferno, to our times. For, we cannot escape them, nor should we have any wish to do so : they are our times (if we make them, we must).

But, truth, you want?

Truth : We would have to stop loving all of our heroes, and there would be none left, and none left to love them. Or, accept them for what they are : a task so impossible you would have to start accepting yourselves...

"Martha was sooo realistic" - said a dumb Barbie I know. (Myself.)

It was not realistic : It was real.

In Martha, everything is! That is what makes it so shocking, and profoundly disturbing, groundbreaking. Hyper-realism. Everything is so real that we must leave out the italics.

Do you not get it? When the male protagonist screams "Martha" from down the stairs : what you are hearing, and seeing, is - in the most blunt and brutal way possible - Fassbinder screaming in atrocity at himself.

Our translations are reflections of our times, and ourselves - and yourselves. In a translation, we start with an act of abuse : to the ones we love the most. 